\title{
An unresolved issue: Diagnosing coronary artery disease in left bundle branch block
}

Dear Editor,

We have read the article published by Vidula et $\mathrm{al}^{1}$ with great interest and enthusiasm. Briefly, in this study they have reported higher sensitivity ( $88 \%$ vs $60 \%)$ and specificity (56\% vs $14 \%$ ) of positron emission tomography (PET) when compared to single-photon emission tomography (SPECT) for diagnosing obstructive coronary artery disease (CAD) in patients with left bundle branch block (LBBB). The diagnostic challenge mainly arises from the high incidence of false-positive septal perfusion defects induced by LBBB. Indeed, many different diagnostic and interpretation methods such as SPECT, stress echocardiography, and exercise stress test have been applied to improve the limited diagnostic accuracy in those with LBBB. ${ }^{2}$ In this context, Vidula et al's report has put new promising results for the diagnosis of CAD in those with LBBB. However, despite the high rate of specificity and diagnostic accuracy of PET compared with SPECT, considerable number of septal perfusion defects remained as a matter of issue in patients with LBBB assessed by PET MPI. Among those non-invasive tests, dobutamine stress echocardiography (DSE) has been found to have particularly higher value of diagnostic accuracy compared to SPECT. ${ }^{2}$ Literately both DSE and PET MPI have comparable values of diagnostic accuracy. ${ }^{1,3}$ Regarding economical aspects of these tests, DSE might be a reasonable option in terms of cost-effectiveness. Although not too much attention has been paid during the last decade, DSE should be considered for the assessment of CAD in patients with LBBB. Accordingly, direct comparison of DSE and PET MRI is warranted to help figuring out the ideal technique for diagnosis of CAD in patients with LBBB. On the other hand, Vidula et al's report emphasize that the matter of septal perfusion in LBBB still remains to be elucidated in future studies.

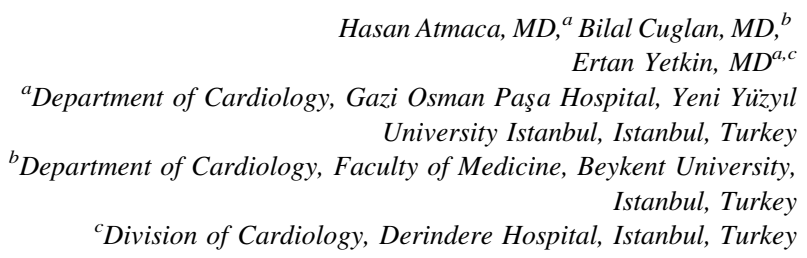

\section{References}

1. Vidula MK, Wiener P, Selvaraj S, Khan MS, Salam UA, Rojulpote C, Metzler SD, Denduluri S, Guerraty M, Julien H, Bravo PE (2020) Diagnostic accuracy of SPECT and PET myocardial perfusion imaging in patients with left bundle branch block or ventricular-paced rhythm. J Nucl Cardiol. https://doi.org/10.1007/ s12350-020-02398-5

2. Yanik A, Yetkin E, Senen K, Atak R, Ileri M, Kural T, Göksel S (2000) Value of dobutamine stress echocardiography for diagnosis of coronary artery disease in patients with left bundle branch blockage. Coron Artery Dis 11:545-48

3. Meredith D, Cremer PC, Harb SC, Xu B, Mentias A, Jaber WA (2019) Initial experience with regadenoson stress positron emission tomography in patients with left bundle branch block: Low prevalence of septal defects and high accuracy for obstructive coronary artery disease. J Nucl Cardiol. https://doi.org/10.1007/ s12350-019-01681-4

Publisher's Note Springer Nature remains neutral with regard to jurisdictional claims in published maps and institutional affiliations. 